\title{
Analisis Kepuasan Pengujung Berdasarkan Tourist Experience ke Daerah Istimewa Yogyakarta
}

\author{
Tarandhika Tantra*, Heppy Millanyani, Ilham Meidarlis Yefri \\ Fakultas Ekonomi dan Bisnis, Program Studi Manajemen, Universitas Telkom, Bandung, Indonesia \\ Email: 1, ${ }^{*}$ ttantra@telkomuniversity.ac.id, ${ }^{2}$ heppymill@telkomuniversity.ac.id, ${ }^{3}$ ilhamyefti@ telkomuniversity.ac.id \\ Email Penulis Korespondensi: ttantra@telkomuniversity.ac.id \\ Submitted: 21/11/2021; Accepted: 29/11/2021; Published: 30/11/2021
}

\begin{abstract}
Abstrak-Indonesia merupakan negara yang indah dengan berbagai destinasi wisata yang menarik. Untuk itu pemerintah mengembangkan 10 New Bali di berbagai tempat di Indonesia agar dapat sejajar dengan negara regional. Yogyakata merupakan destinasi wista yang ikonik dan menarik minat berkunjung wisatawan. Agar Yogyakarta dapat bersaing dengan destinasi 10 New Bali, perlu dilakukan penelitian untuk mengetahui bagaimana tingkat kepuasan para wisatawan di Yogyakarta berdasarkan pengalaman berkunjung serta mengetahui faktor apa saja yang harus ditingkatkan untuk dapat bersiang. Penelitian ini menggunakan metode kuantitatif dengan teknik pengumpulan data menggunakan penyebaran kuisoner kepada 385 responden yang merupakan wisatawan Daerah Istimewa Yogyakarta. Teknik pengolahan data menggunakan Importance Performance Analysis dan Customer Satisfaction Index terhadap Tourist Experience. Importance Performance Analysis untuk mengetahui aspek dan indikator apa yang harus ditingkatkan kinerjanya dalam sektor pariwisata Yogyakarta. Sedangkan Customer Satisfaction Index untuk mengetahui tingkat kepuasan wisatawan Yogyakarta. Dari analisis data yang dilakukan dapat diketahui bahwa tingkat kepuasan wisatawan Daerah Istimewa Yogyakarta berdasarkan Tourist Experience sebesar 84,9\%. Indikator dengan kinerja yang paling memuaskan adalah hedonis dan indikator dengan kinerja kurang memuaskan adalah relasional. Berdasarkan hasil penelitian ini diharapkan kepada stakeholder pariwsata Yogyakarta memberikan edukasi dan sosialisasi kepada masyarakat untuk berinteraksi dan berkomunikasi agar lebih baik kepada para wisatawan
\end{abstract}

Kata Kunci: Customer Behavior; Customer Satisfaction; Customer Satisfaction Index; Importance Performance Analysis; Tourist experience

Abstract-Indonesia is a beautiful country with a variety of interesting tourist destinations. The government developed 10 New Bali in various places in Indonesia to align with regional countries. Yogyakarta is an iconic destination and attracts tourists. In order for Yogyakarta to compete with the destinations of $10 \mathrm{New}$ Bali, research needs to be done to find out how the level of satisfaction of tourists in Yogyakarta based on the visiting experience and know what factors must be improved to be able to move. This study uses quantitative methods with data collection techniques using questionnaires to 385 respondents who are tourists of Yogyakarta. Data processing techniques use Importance Performance Analysis and Customer Satisfaction Index to Tourist Experience. Importance Performance Analysis to determine what aspects and indicators should be improved performance in the Yogyakarta tourism sector. At the same time, the Customer Satisfaction Index to find the level of satisfaction of Yogyakarta tourists. From the analysis of data conducted, it can be known that the satisfaction rate of tourists of Yogyakarta Special Region based on Tourist Experience is $84.9 \%$. Indicators with the most satisfactory performance are hedonistic, and indicators with less satisfactory performance are relational. Based on the results of this study, it is expected that Yogyakarta stakeholders provide education and socialization to the community to interact and communicate better with tourists.

Keywords: Customer Behavior; Customer Satisfaction; Customer Satisfaction Index; Importance Performance Analysis; Tourist experience

\section{PENDAHULUAN}

Indonesia memiliki alam yang indah dengan beragam destinasi warisan budaya. Kondisi ini merupakan sebuah keunggulan kompetitif bagi industri pariwisata agar bersaing secara global. Oleh karena itu, meningkatkan sektor pariwisata untuk dapat bersaing secara global merupakan hal sangat penting (Kusumah, 2020). Sektor pariwisata di negara-negara regional seperti Thailand, Malaysia, dan Singapura telah menjadi salah satu kontributor utama PDB, sumber pendapatan masyarakat, dan pembangunan infrastruktur (Khan et al., 2017).

Untuk dapat berasaing, pada tahun 2018 Pemerintah Indonesia memperkenalkan program 10 New Bali sebagai tujuan pariwisata prioritas nasional. Diantaranya terdapat lima destinasi super prioritas adalah Kuta Mandalika, Borobudur, Danau Toba, Tanjung Lesuang, dan Labuan Bajo. Diharapkan destinasi ini akan menarik banyak pengunjung sama seperti Bali, yang berhasil menarik empat juta pengunjung (BKPM, 2019). Program ini juga diharapkan dapat memicu daerah lain di Indonesia untuk mengembangkan destinasi wisatanya agar dapat bersaing.

Daerah Istimewa Yogyakarta merukapan destinasi wisata yang ikonik yang populer bagi wisatawan Indonesia maupun internasional. Warisan budaya benda maupun tak benda yang masih terjaga dan nilai - nilai tradisional yang masih melekat pada masyarakatnya menjadi daya tarik utama. Daerah Istimewa Yogyakarta menggunakan konsep city branding dengan tagline "Jogja Istimewa" agar mudah di ingat oleh para wisatawan. Ketertarikan para wisatawan untuk berkunjung ke destinasi wisata dipengaruhi oleh beberapa faktor, diantara adalah keindahan pesona alamnya, penduduk sekitar yang ramah dan adanya hiburan yang terjangkau (Vellas dan Bacheler, 2008). Sedangkan wisatawan mancanegara mencari sesuatu yang berbeda dan unik dari negara asal ketika memutuskan mengunjungi suatu daerah wisata (Adilaksono, 2014).

Pembangunan dan pengembangan pada daerah wisata dilakukan untuk memenuhi kepuasan wisatawan. Kepuasaan wisatawan terbentuk berdasarklan penilaian dari perbedaan ekspektasi sebelum dan sesudah wisatawan 
mengunjungi suatu obyek wisata (Sadeh et al, 2012; Widagdyo, 2017; Wiratini et al., 2018). Ketika wisatawan merasa kepuasan yang tinggi makan akan mendorong wisatawan berkunjung kembali ke daerah tersebut (Munhurrun et al, 2014). Sheng \& Chen (2013) menyatakan bahwa pengalaman berwisata (tourist experience) merupakan bentuk akumulatif peristiwa psikologis, sebagaimana yang tampak pada perspektif psikologi di mana mencakup keinginan sebelum perjalanan, persepsi sepanjang perjalanan, dan kenangan sesudah selesai perjalanan.

Daerah Istimewa Yogyakarta masih menjadi desitnasi wisata primadona bagi masyarakat Indonesia dan juga mancanegara. Namun seiring dengan perkembangan wisata di daerah lainnya di Indonesai terutama pengembangan program $10 \mathrm{New}$ Bali, D.I. Yogyakarta perlu melakukan pembenahan wisatanya secara berkelanjutan. Kepuasa wisatawan yang terbentuk berdasarkan tourist experience perlu dijaga dan terus ditingkatkan. Untuk itu penelitian ini akan mengukur tingkat kepuasan wisatawan berdasarkan tourist experience, serta mengetahui aspek - aspek yang perlu ditingkatkan agar wisata D.I. Yogyakarta dapat terus unggul dan dapat bersaing dengan destinasi wisata prioritas pemerintah.

\section{METODE PENELITIAN}

\subsection{Tourism Experience}

Menurut Sheng \& Chen (2013) menyatakan pengalaman berwisata dalam bentuk akumulatif peristiwa psikologis, sebagaimana yang tampak pada perspektif psikologi di mana mencakup keinginan sebelum perjalanan, persepsi sepanjang perjalanan, dan kenangan sesudah selesai perjalanan. Menurut Rageh et al (2013) pengalaman wisata dibagi menjadi beberapa dimensi. Dimensi pertama adalah kenyamanan (comfort) yang berkaitan erat dengan pengalaman wisatawan untuk merasa rileks, tenang dan nyaman.

Dimensi kedua merupakan pendidikan (educational), dimana berwisata dapat dijadikan pengalaman edukasi atau belajar sambil bermain (Parker, 2016), serta gabungan dari eksplorasi, penjelajahan, stimulasi mental, semangat dan kesenangan. Terdapat bukti kuat yang menunjukan pengalaman pendidikan yang disediakan di industri pariwisata (Rageh et al., 2013). Dimensi ketiga merupakan hedonis yang merupakan simbol dari kesenangan, kegembiraan, semangat, dan memori kenangan. Aspek hedonis didapatkan oleh pengunjung ketika mendapatkan pengalaman berpetualang, makanan yang lezat dan suasana hotel atau penginapan yang mewah (Rageh et al., 2013).

Pada dimesi ke empat, hal baru (novelty) membentuk suatau sensasi baru dari suatu pengalaman. Kebutuhan akan hal baru mengarah kepada keinginan untuk berkelana ke tempat baru yang belum pernah dikunjungi, mencari pengalaman baru ditempat asing. Dalam kunjungan wisata, konsumen juga ini mendapatkan pengakuan (recognition) - sebagai dimensi ke lima, seperti merasa disambut oleh staf hotel, karyawan hotel, atau biro perjalanan yang mereka gunakan. Perlakuan seperti ini membuat para wisatawan merasa penting dan merasa dihargai (Rageh et al., 2013). Dimensi keenam dari tourist experience adalah relasional, dimana pengunjung berinteraksi dengan individu lain yang menarik sehingga terjalin hubungan yang lebih dekat. Hubungan sosial yang terjalin ini merupakan pengalaman yang menarik bagi wisatawan (Rageh et al., 2013).

Dalam kepariwisataan, terdapat faktor keamanan dan wisata disepakati memiliki hubungan yang kuat dalam menciptakan tourism experience. Wisatawan harus merasa nyaman selama melakukan kegiatan wisata dan aman dari tindakan kriminal. Dengan demikian kemanan menjadi dimensi ketujuh pada turism experience. Selanjutnya menurut Rageh et al. (2013) keindahan merupakan aspek dari idealisasi pengalaman dimana suara, objek, dan konsep yang diyakini mempunyai kualitas dari kesempurnaan. Keindahan (beauty) manjadi dimensi ke delapan dalam tourist experience.

\subsection{Kepuasan Wisatawan}

Menurut Kotler dan Keller (2016) kepuasan wisatawan merupakan tingkat perasaan seseorang sesudah membandingkan antara kinerja atau hasil yang telah dirasakan dibandingkan dengan harapan. Terciptanya kepuasan pelanggan tergantung pada kinerja barang dan jasa sesuai harapan pelanggan sesudah pembelian. Giese \& Cote (2000) menegaskan bahwa kebutuhan untuk dapat menentukan tingkat kepuasan berdasarkan konteks yang akan dievaluasi. Mereka mengidentifikasi tiga elemen dasar konteks, yaitu respons terhadap penilaian emosional; aspek khusus dari layanan (pertemuan layanan tertentu); saat tertentu dalam waktu (misalnya, segera setelah layanan dilakukan).

Penggunaan Tourist Experience sebagai penilaian kepuasan sudah dilakukan oleh pada beberapa penelitian, namun didapat hasil yang beragam. Penelitian oleh Malone et al., (2014) dan Kim dan Ritchie (2014) memperlihatkan kepuasaan wisatawan pada unsur hedonism merupakan hal yang sangat penting pada tourist experience. Namun Mei (2014) dan Valenzuela dan Chandralal (2013) yang mengemukakan bahwa novelty merupakan dimensi yang berperan paling dominan pada tourism experience.

Dalam industri pariwisata, pentingnya mengetahui pengalaman pelanggan sudah menjadi hal yang seharusnya diperhatikan, pengalaman pelanggan dapat menjadi indikator para stakeholder industri pariwisata untuk melakukan perbaikan layanan, jasa, dan produk dengan tujuan memberikan kepuasan wisatawan. Berdasarkan dimensi yang mendasari faktor pengalaman pelanggan antara lain, kenyamanan, Pendidikan, hedonis, novelty, relasional, pengakuan, keindahan dan keamanan (Rageh et al, 2013). Kedelapan dimensi tersebut akan menjadi variabel penetilian untuk mengetahui kepuasan wisatawan di Daerah Istimewa Yogyakarta. Pada penelitian ini penulis 
menggunakan teori yang di paparkan oleh Rageh et al., (2013) karena mengungkapkan kepuasan wisatawan terus berkembang dan informasi yang mendalam untuk memajukan pemahaman tentang dimensi tourist experience.

\subsection{Pengumpulan Data}

Data didapat melalui penyebaran kuesioner dengan menggunakan google form yang dilakukan selama periode satu bulan di bulan Juli 2021. Populasi penelitian ini merupakan semua orang yang pernah berkunjung ke Daerah Istimewa Yogyakarta. Sampel pada penelitian ini berjumlan 385 responden yang pernah mengunjungi Daerah Istimewa Yogyakarta. Teknik sampling pada penelitian ini menggunakan teknik non probability sampling dengan pendekatan secara purposive sampling

\subsection{Importance Performance Analysis}

Pada penelitian ini teknik analisis data yang digunakan adalah Importance Performance Analysis yang merupakan pendekatan pada grafik yang menunjukkan kepentingan (importance) dari beberapa atribut dengan kinerja (performance) perusahaan atau produk melalui penggunaan matriks (Ng So Kiu, 2013). Skor kepentingan dan dan skor kinerja diletakkan pada plot matriks yang terdiri dari empat kuadran yang berbeda. Atribut yang terletak pada plot dengan kepentingan tinggi dan kinerja rendah diidentifikasi untuk meningkatkan kualitas layanan.

Pada teknik Importance Performance Analysis, responden diminta melakukan penilaian tingkat kepentingan (Importance) dan kinerja (Performance) pada suatu perusahaan, kemudian hasil nilai rata-rata tingkat kepenitngan dan kinerja dianalisis menggunakan Importance Performance Analysis Matrix dimana sumbu $\mathrm{x}$ mewakili kinerja (Performance) dan sumbu y mewakili kepentingan (Importance) yang akan ditampilkan pada gambar di bawah ini:

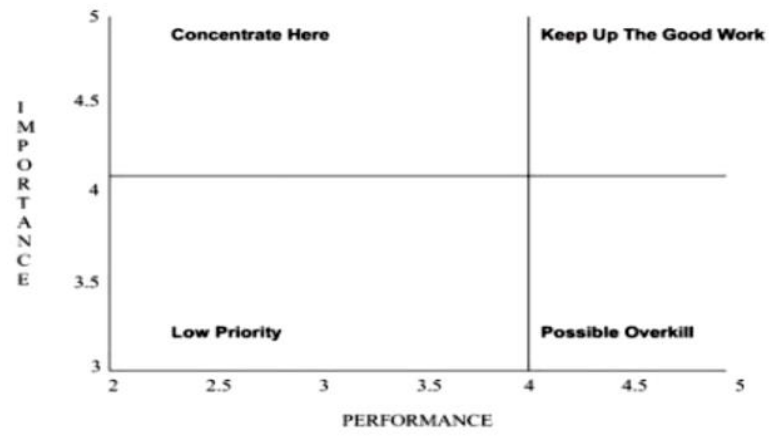

Gambar 1. Importance Performance Analysis Matrix

\subsection{Costumer Satisfaction Index}

Customer Satisfaction Index merupakan informasi dan data yang berisi tentang tingkat kepuasan konsumen, dimana data didapatkan melalui hasil pengukuran kualitatif dan kuantitatif terhadap opini konsumen untuk mendapatkan layanan masyarakat melalui perbandingan realita dan harapan (Rondonuwu, 2013). Menghitung Customer Satisfaction Index dengan rumus (Pohandry et al., 2013):

$$
C S I=\frac{T}{4 Y} 100 \%
$$

Penjelasan dari rumus diatas adalah, nilai 4 dari nilai $4 \mathrm{Y}$ ialah nilai maksimum yang digunakan pada skala pengukuran. Nilai maksimum untuk CSI adalah $100 \%$. Apabila nilai CSI 50\% atau lebih rendah menjelaskan kinerja yang kurang baik atau pelanggan maupun customer belum puas. Apabila nilai CSI 80\% atau lebih tinggi mengartikan pelanggan merasa puas pada kinerja pelayanan (Pohandry et al., 2013).

\section{HASIL DAN PEMBAHASAN}

\subsection{Karakteristik Responden}

Responden dalam penelitian ini berjumlah 385 responden yang terdiri dari wisatawan yang pernah berwisata ke Daerah Istimewa Yogyakarta. Pengumpulan data dilakukan dengan menyebarkan kuisoner kepada responden yang cocok dan sesuai dengan kriteria sebagai wisatawan yang pernah berkunjung dengan tujuan berwisata ke Daerah Istimewa Yogyakarta. Penyebaran kuisoner dilakukan pada bulan Juli sampai dengan bulan Agustus 2021. Karakteristik responden dirangkum pada tabel 1.

Tabel 1. Data Responden

\begin{tabular}{ccc}
\hline Variabel & Jumlah & Persentase \\
\hline Jenis Kelamin & 146 & 38 \\
$-\quad$ Perempuan & 146
\end{tabular}


Ekonomi, Keuangan, Investasi dan Syariah (EKUITAS)

Vol 3, No 2, November 2021, Hal 211-218

ISSN 2685-869X (media online)

DOI 10.47065/ekuitas.v3i2.1122

\begin{tabular}{|c|c|c|c|}
\hline \multicolumn{2}{|r|}{ Variabel } & \multirow{2}{*}{$\begin{array}{l}\text { Jumlah } \\
239\end{array}$} & \multirow{2}{*}{$\begin{array}{l}\text { Persentase } \\
62\end{array}$} \\
\hline - & Laki-laki & & \\
\hline \multicolumn{4}{|l|}{ Usia } \\
\hline- & $<20$ Tahun & 27 & 7 \\
\hline - & $21-25$ Tahun & 294 & 76,5 \\
\hline - & $26-30$ Tahun & 51 & 13,2 \\
\hline- & $31-35$ Tahun & 10 & 2,6 \\
\hline- & $>36$ tahun & 3 & 0,8 \\
\hline \multicolumn{4}{|c|}{ Pekerjaan } \\
\hline- & Pelajar/Mahasiswa & 216 & 55,8 \\
\hline- & Wiraswasta & 42 & 11,4 \\
\hline- & Pegawai/Karyawan & 96 & 24.8 \\
\hline- & Lainnya & 31 & 8 \\
\hline
\end{tabular}

Tabel 1 menunjukkan mayoritas dari responden adalah 62 persen dari berjenis kelamin laki - laki dengan rentang usia terbesar $21-25$ tahun sebanyak 76,4 persen, dan sebanyak 55,8 persen berstatus pelajar atau mahasiswa. Dari data ini dapat dilihat bahwa Generasi Milenial dan Gen-Z mendominasi pelaku perjalanan ke Daerah Istimewa Yogyakarta.

\subsection{Analisis}

Setelah melakukan penyebaran kuisoner, peneliti melakukan input data yang sudah diperoleh dari kuisoner pada microsotf excel dan selanjutnya mencari rata rata nilai pada masing-masing indikator yang akan ditampilkan pada tabel 3. Berdasarkan hasil yang didapat, memperlihatkan hasil perolehan nilai rata rata setiap indikator variabel Tourist Experience dari kuisoner yang sudah disebarkan kepada 385 responden. Dari penyebaran kuisoner ini didapatkan hasil untuk kinerja sebesar 35,59 dan untuk kepentingan sebesar 37,35, dan untuk nilai rata rata kinerja yaitu 3,2 sedangkan nilai rata rata untuk kepentingan yaitu 3,39 .

Tabel 2. Tabel Rata - rata Variable Tourist Experience

\begin{tabular}{lcccl}
\hline Dimensi & Kode Item & Kepentingan (Y) & Kinerja (X) & $\begin{array}{l}\text { Skor (T) } \\
(\mathrm{X} x \text { Y })\end{array}$ \\
\hline Kenyamanan & CF-1 & 3,43 & 3,38 & 11,593 \\
Pendidikan & CF-2 & 3,38 & 3,32 & 11,221 \\
Hedonis & ED-3 & 3,36 & 3,3 & 11,088 \\
Novelty & HE-4 & 3,45 & 3,4 & 11,730 \\
Pengakuan & HE-5 & 3,4 & 3,24 & 11,016 \\
Relasional & NV-6 & 3,36 & 3,26 & 10,953 \\
Keamanan & RC-7 & 3,36 & 3,17 & 10,651 \\
Keindahan & RL-8 & 3,5 & 3,1 & 10,850 \\
& SC-9 & 3,31 & 2,9 & 9,559 \\
\multicolumn{1}{c}{ Total } & BY-10 & 3,42 & 3,23 & 11,046 \\
\multicolumn{1}{c}{ Rata - rata } & BY-11 & 3,38 & 3,29 & 11,120 \\
\hline
\end{tabular}

Pada Gambar 2 di dalam matrix Importance Performance Analysis dibagi menjadi 4 bagian kuadran, Pada bagian di kuadran II menandakan kinerja sektor pariwisata di Daerah Istimewa Yogyakarta sudah dapat memenuhi tingkat kepentingan yang diharapkan oleh para wisatawan, indikator yang terdapat di dalam kuadran II adalah 1, 2, 4, 5,10 , dan 11. Kuadran II adalah wilayah yang dinilai memiliki bagian penting, namun kinerjanya dinilai masih belum

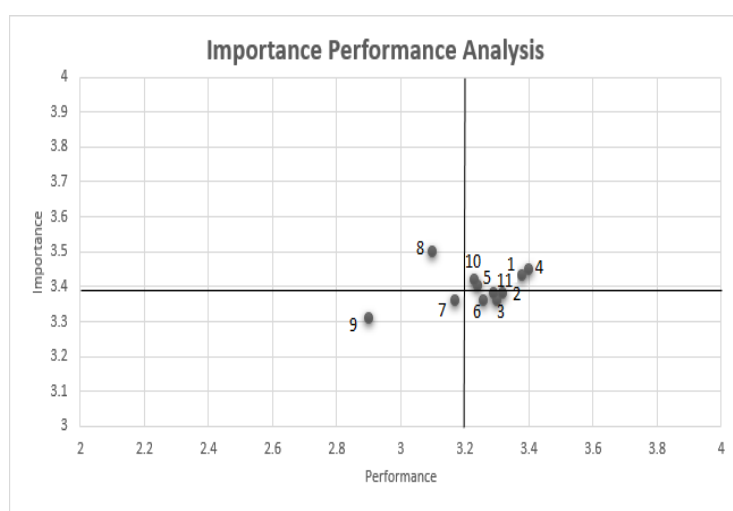


memuaskan. Indikator yang ada di dalam kuadran II adalah nomor 8 yaitu masyarakat Provinsi Daerah Istimewa Yogyakarta ramah terhadap wisatawan.

\section{Gambar 2. Importance Perfoemance Analysis Matrix}

Pada bagian di kuadran III adalah sektor yang dianggap tidak menjadi fokus utama para wisatawan dan kinerja sektor pariwisata juga tidak menunjukkan kinerja yang memuaskan, indikator yang ada di bagian kuadran III yaitu nomor 7 dan 9. Pada bagian di kuadran IV adalah sektor yang dianggap tidak penting oleh para wisatawan namun kinerja sektor pariwisata Daerah Istimewa Yogyakarta menunjukkan kinerja memuaskan, indikator yang terdapat di dalam kuadran IV adalah 3 dan 6.

Mayoritas indikator di dalam matrix Importance Performance Analysis terdapat di dalam bagian kuadran I yang berarti kinerja dari sektor pariwisata di Daerah Istimewa Yogyakarta sudah mampu memenuhi tingkat kepentingan ekspektasi para wisatawan. Namun terdapat indikator yang berada di dalam bagian kuadran II yaitu indikator nomor 8 yang dimana sektor pariwisata di Daerah Istimewa Yogyakarta perlu ditingkatkan kinerjanya.

Berdasarkan tabel 3 menunjukkan hasil perkalian dari masing-masing nilai rata-rata pada indikator subvariabel Tourist Experience. Total nilai dari kinerja (X) sebesar 35,59 dan total nilai kepentingan (Y) sebesar 37,35. Sehingga diperoleh total skor (T) kinerja dan kepentingan sebesar 120,867. Kemudian dilakukan pengolahan lebih lanjut yang bertujuan mengetahui puas atau tidak puasnya wisatawan yang sudah berkunjung ke Daerah Istimewa Yogyakarta. Berikut ini merupakan Rumus 1 dari Customer Satisfaction Index.

$$
\begin{gathered}
C S I=\frac{T}{4 Y} 100 \% \\
C S I=\frac{120,867}{(4 \times 35,59)} 100 \% \\
C S I=\frac{120,867}{142,36} 100 \% \\
C S I=84,9 \%
\end{gathered}
$$

Hasil perhitungan di atas memeprlihatkan nilai persentase sebesar 84,9\%. Menurut Rondonuwu (2013), tingkat kepuasan wisatawan atau konsumen berada pada kategori puas apabila nilai tersebut $>80 \%$. Jadi dapat disimpulkan wisatawan yang berkunjung ke D. I Yogyakarta merasa puas terhadap pengalaman yang didapatkan selama mereka berwisata berdasarkan Tourist.

\subsection{Pembahasan}

\subsubsection{Importance Performance Analysis Kuadran I}

Kuadran I yaitu bagian yang dianggap penting dan kinerjanya sudah sesuai dengan harapan para wisatawan, yang berarti kinerja indikator yang berada pada kuadran I ini dapat disebut efesien dan wisatawan puas dengan indikator pada kuadran I. Indikator yang terdapat pada kuadran I yaitu merasa nyaman saat berwisata, merasa rileks setelah berkunjung, merasa senang saat berwisata, mendapatkan pengalaman yang tidak terlupakan, destnasi wisata sangat indah dan merasa kagum dengan dengan keindahan Daerah Istimewa Yogyakarta. Makna dari faktor-faktor tersebut yaitu responden yang berkunjung ke Daerah Istimewa Yogyakarta merasakan sudah terpenuhinya harapan mereka dengan indikator diatas terkait hedonis, kenyamanan dan keindahan

\subsubsection{Importance Performance Analysis Kuadran II}

Kuadran II merupakan bagian penting, namun kinerjanya dinilai masih belum efesien dan masih belum memuaskan harapan wisatawan, yang berarti kinerja pada kuadran I ini belum sesuai harapan. Indikator yang berada pada kuadran I ini yaitu masyarakat Daerah Istimewa Yogyakarta ramah terhadap para wisatawan, artinya wisatawan sebagai responden yang berwisata di Daerah Istimewa Yogyakarta menganggap masyarakat Daerah Istimewa Yogyakarta belum ramah sesuai harapan.

Belum sesuainya harapan wisatawan terhadap keramah-tamahan masyarakat Daerah Istimewa Yogyakarta kepada wisatawan dapat disebabkan beberapa faktor, yang pertama kurangnya pengetahuan masyarakat disekitar destinasi dan objek wisata mengenai, etika dan cara berkomunikasi terhdapap wisatawan. Yang kedua, permasalahan perbedaan adat, budaya dan sosial dalam berinteraksi menyebabkan adanya perbedaan persepsi antara wisatawan dan masyarakat sekitar. Faktor terakhir adalah kurangnya kegiatan sosialisasi dari pemerintah untuk mengedukasi dan memberikan pengarahan kepada keseluruhan masyarakat yang berada di sekitar destinasi dan objek wisata bagaimana cara yang baik untuk berkomunikasi dan berinteraksi kepada wisatawan (Yudianti, 2015)

Untuk memperbaiki faktor faktor yang menjadi kendala dalam variabel relasional tersebut, stakeholder dalam bidang pariwisata bisa memberikan sosialisai dan edukasi kepada para masyarakat yang berada di sekitar destinasi dan objek wisata untuk berkomunikasi dan berinteraksi sebagaimana mestinya untuk memberikan kesan bahwa sebenarnya masyarakat di Daerah Istimewa Yogyakarta begitu ramah terhadap wisatawan. Tujuan dari memberikan sosialisasi kepada masyarakat adalah untuk melakukan kontrol terhadap usaha yang dilakukan, apabila kegiatan usaha yang dilakukan mempunyai kekurangan dalam sektor tertentu, stakeholder sehendaknya melakukan evaluasi dan inovasi untuk tercapainya tujuan yang diinginkan (Amalana, 2016) 
Faktor relasional menjadi penting karena wisatawan berharap masyarakat Daerah Istimewa Yogyakarta ramah terhadap wisatawan. Wisatawan akan lebih menyukai pelayanan yang ramah, penjual yang menguasai tentang produk yang ditawarkan, memberikan solusi daripada sekedar kerja cepat.

\subsubsection{Importance Performance Analysis Kuadran III}

Kuadran III adalah bagian yang diharapkan tidak terlalu penting dan pada kenyataannya kinerjanya juga tidak terlalu tinggi. Indikator pada kuadran III yaitu pelayanan tempat pariwisata dan keamanan ketika berwisata. Artinya pelayanan dan rasa aman dianggap tidak terlalu penting oleh para wisatawan dan kinerja pelayanan di tempat pariwisata serta rasa aman juga tidak terlalu efektif.

Belum efektifnya pelayanan yang dirasakan saat berwisata disebabkan oleh tidak meratanya pembangunan layanan infrastruktur di Daerah Istimewa Yogyakarta, contohnya pembangunan jalan dan fasilitias umum yang belum merata di seluruh Daerah Istimewa Yogyakarta dimana hal ini dapat menciptakan persepsi wisatawan bahwa pemerintah Daerah Istimewa Yogyakarta belum sepenuhnya siap mengembangkan industri pariwisata (Syakdijah,2017). Faktor kedua yang menyebabkan pelayanan kurang maksimal adalah kurangnya tenaga kerja yang menguasai keahlian dalam bidang pariwisata (Syakdijah,2017)

Rendahnya harapan wisatawan terhadap indikator keamanan disebabkan oleh maraknya aksi begal (klitih). Sehinga dengan maraknya aksi kilitih ini maka para wisatawan sudah mengetahui faktor keamanan di Daerah Istimewa Yogyakarta memang tidak aman, maka persepsi yang terbentuk pada wisatawan adalah Daerah Istimewa Yogyakarta tidak aman karena adanya aksi klitih. Sehingga untuk meningkatkan kinerja pelayanan dan keamanan, stakeholder pariwisata sebaiknya melakukan pemerataan pembangunan infrastruktur di seluruh daerah yang langsung menjadi akses untuk menuju ke destinasi dan objek pariwisata, selanjutnya peningkatan kualitas tenaga kerja yang sesuai dengan standar operasional dalam memberikan pelayanan kepada wisatawan. Peningkatan keamanan dapat dilakukan dengan cara melakukan peningkatan aktivitas sweeping pada jam malam ketika waktu libur panjang dan libur akhir tahun. Wisatawan sangat mengharapkan keamanan untuk menghindari rasa cemas selama berwisata, yang mengkhawatirkan stress perjalanan dan keselamatan selama mereka berwisata.

Upaya peningkatan indikator pada kuadran III ini bertujuan untuk meningkatkan kepuasan wisatawan, meskipun tidak diaggapap penting oleh wisatawan sebaiknya stakeholder pariwisata juga memperhatikan indikator tersebut karena pembangunan infrastruktur, dan layanan kualitas yang baik dapat meningkatkan kepuasan wisatawan (Poerwanto, 2004).

\subsubsection{Importance Performance Analysis Kuadran IV}

Kuadran IV adalah bagian yang dianggap tidak terlalu penting oleh para wisatawan namun mempunyai kinerja yang baik. Indikator yang terdapat di Kuadran IV adalah mendapatkan pengetahuan baru ketika berwisata dan mendapatkan pengalaman baru setelah berwisata. Artinya wisatawan tidak menggap penting pengetahuan dan pengalaman baru ketika nanti mereka berwsiata, akan tetapi pada kenyataannya kinerja yang diberikan oleh tempat pariwisata Daerah Istimewa Yogyakarta cukup baik

\subsubsection{Customer Satisfaction Index}

Berdasarkan hasil perhitungan pada tabel 4.2 Customer Satisfaction Index diperoleh hasil sebesar 84,9\%, yang berarti hasil perhitungan tersebut diatas $80 \%$. Dapat disimpulkan bahwa tingkat kepuasan wisatawan Daerah Istimewa Yogyakarta terletak pada posisi lebih baik atau wisatawan merasa puas ketika berwisata di Daerah Istimewa Yogyakarta. Indikator yang paling tinggi nilai total akhirnya adalah indikator hedonis dengan pernyataan mengenanai wisatawan merasa senang saat berwisata di Daerah Istimewa Yogyakarta dengan total skor sebesar 11,730. Indikator dengan nilai total skor paling rendah adalah keamanan dengan pernyataan saya merasa aman saat berwisata di Daerah Istimewa Yogyakarta dengan total skor sebesar 9,599. Berdasarkan hasil penilaian setiap indikator menggunakan Customer Satisfaction Index poin pernyataan yang paling mempengaruhi adalah poin pernyataan pada indikator hedonis, sedangkan poin pernyataan dengan pengaruh paling kecil adalah indikator keamanan.

\section{KESIMPULAN}

Berdasarkan hasil penelitian ini dengan menggunakan metode Importance Performance Analysis dan Customer Satisfaction Index, maka dapat disimpulkan bahwa kepuasan wisatawan berdasarkan tourist experience dengan menggunakan metode Importance performance Analysis dimensi yang dianggap penting dan kinerja sektor pariwisata yang sudah memenuhi ekspektasi wisatawan terdapat pada kuadran I, yaitu kenyamanan, hedonis, dan keindahan. Sedangkan, perhitungan kepuasan wisatawan menggunakan metode Customer Satisfaction Index mempunyai presentase sebesar $84,9 \%$. Yang berarti bahwa wisatawan puas selama berwisata di Daerah Istimewa Yogyakarta. Faktor prioritas yang harus ditingkatkan berdasarkan tourist experience menggunakan metode Importance Performance Analysis adalah variabel yang terletak pada kuadran II yaitu variabel relasional dengan indikator 
masyarakat Daerah Istimewa Yogyakarta begitu ramah terhadap wisatawan. Pengalaman relasional yang melibatkan orang lain dalam berinteraksi selama berwisata menjadi faktor penting yang diharapkan oleh wisatawan.

\section{REFERENCES}

Adilaksono, Braviono Arief, Susilo,Ahimsa Soekartono (2014) Majalah ASEAN Edisi 6: KTT ASEAN Pertama Presiden Joko Widodo. Jakarta : Direktorat Jendral Kerja Sama ASEAN Kementrian Luar Negeri RI

A Prasetio, Ferinia, R., Tanjung, R., Purba, B., Lestari, N., Mastuti, R., Utami, N. R\& Dewi, I. K. (2021). Perilaku Konsumen Kepariwisataan. Yayasan Kita Menulis.

Anonim. (2020, 2 Februari) Kontribusi Pariwisata Bagi Perekonomian RI. Diakses: https://www.cnnindonesia.com/ekonomi/20200226121314-532478265/menghitung-kontribusi-sektor-pariwisata-bagiekonomi-ri [31 Mei 2021] Bagus, I Gusti. (2014). Pengantar Industri Pariwisata. Yogyakarta: CV Budi Utama.

Bappeda Provinsi Jogja .(2021) Destinasi dan Objek Wisata. Diakses dari http://bappeda.jogjaprov.go.id/dataku/data_dasar/cetak/211-pariwisata [31 Mei 2021]

Bappeda Provinsi Jogja. (2021) Jumlah Hotel di Daerah Istimewa Yogyakarta. Diakses dari http://bappeda.jogjaprov.go.id/dataku/data_dasar/cetak/212-jumlah- hotel [31 Mei 2021]

Bappeda Provinsi Jogja. (2021) Jumlah Restoran dan Rumah Makan di Daerah Istimewa Yogyakarta. Diakses dari http://bappeda.jogjaprov.go.id/dataku/data_dasar/cetak/218-restoran-dan-rumah- makan [31 Mei 2021]

Bappeda Provinsi Jogja. (2021) Jumlah Agen Biro Perjalanan Wisata. Diakses dari http://bappeda.jogjaprov.go.id/dataku/data_dasar/index/222-jumlah-perusahaan- cabang-agen-biro-perjalanan-wisata [31 Mei 2021]

Bejo Siswanto. 2013. Manajemen Tenaga Kerja Indonesia, Pendekatan Administratif dan Operasional, Hal 291. Bumi Aksara, Jakarta.

BKPM. (2019). All You Need to Know about the 10 New Bali Project in Indonesia. Badan Koordinasi Penanaman Modal. https://www.investindonesia.go.id/en/article-investment/detail/all-you-need-to-know-about-the-10-new-bali-project-inindonesia

Cahyani Agnesia Mega. (2019) Segmentasi Pasar Turisme Yogyakarta: Klasifikasi Gaya Hidup Wisatawan Domestik. eProceeding of Management : Vol.6, No.2

Dinata, Regi. (2019, 24 Desember) Libur Natal dan Tahun Baru, Kemacetan di Yogyakarta. Diakses dari https://ayoyogya.com/read/2019/12/24/38154/libur-nataru-kemacetan-di-yogyakarta-jadi-trending [31 Mei 2021]

Dwyer, Robert F., dan Tanner, John F. (2009). Business Marketing: Connecting Strategy, Relation and Learning (4th Ed.). New York - USA: McGraw Hill, Inc.

Ebert, Griffin. 2013. Bisnis, ed.8. Alih Bahasa: Soermarnagara, (2012). Salemba Empat, Jakarta.

Giese \& Cote. 2000. Academy of Marketing Science Review. Defining Consumer Satisfaction Volume 2000 No. 1

Handoko, T. Hani. 2016. Manajemen Personalia dan Sumber Daya Manusia. Yogyakarta: BPFE

Haryanto, J. T. (2014). Model pengembangan ekowisata dalam mendukung kemandirian ekonomi daerah studi kasus provinsi DIY. Jurnal Kawistara, 4(3).

Hasibuan, Malayu SP. (2016). Manajemen Sumber Daya Manusia, Cetakan keempatbelas, Jakarta ,Penerbit : Bumi Aksara.

Indrawati. (2015). Metodologi Penelitian Manajemen dan Bisnis Konvergensi Teknologi Komunikasi dan Informasi, Bandung: PT Refika Aditama

Ismayanti. (2010). Pengantar Pariwisata. Jakarta: PT Gramedia

Janati, Catur. (2021, 13 Februari) Waspada! Sepanjang Bantaran Sungai di Kota Jogja Rawan Banjir. Diakses dari https://jogjapolitan.harianjogja.com/read/2021/02/13/510/1063556/waspada- sepanjang-bantaran-sungai-di-kota-jogjarawan-banjir [31 Mei 2021]

Khan, J. H., Haque, A., Rahman, M. S., Hahm, J. J., Taschi, A. D. D., Hair Jr, J. F., \& Liang, P. (2017). A retrospective view of electronic word-of-mouth in hospitality and tourism management. International Journal of Culture, Tourism and Hospitality Research, 26(2), 211-240. https://doi.org/10.5829/idosi.mejsr.2013.14.12.2250

Kim, J. H., Ritchie, J. R. B., dan McCormick, B. 2012. "Development of a scale to measure memorable tourism experiences". Journal of Travel Research, Vol.51 No.1, pp. 12-25.

Kotler, Phillip dan Kevin Lane Keller.(2016). Manajemen Pemasaran edisi 12 Jilid 1 \& 2.Jakarta: PT. Indeks.

Kotler, Philip and Garry Amstrong, 2018. Priciple Of Marketing, 15 th ed, Pearson prentice hall, New York.

Kurdějov. (2017). 20 Th International Colloquium on Regional Sciences Conference Proceedings Masaryk University Faculty of Economics and Administration Department of Regional Economics and Administration

Kusumah, E. P. (2020). INTENSI PEMILIHAN WISATA BERKELANJUTAN DI PULAU BELITUNG: PENGETAHUAN PARIWISATA SEBAGAI VARIABEL MODERASI. Jurnal Ekonomi Bisnis dan Kewirausahaan (JEBIK), 9(1), 1-16.

Luţ, D. M. (2018). The experience theory in the context of tourism research. Quaestus Multidisciplinary Research Journal, 12, 153160.

Moerwanto, A. S., \& Junoasmono, T. (2017). Strategi Pembangunan Infrastruktur Wisata Terintegrasi. Jurnal HPJI (Himpunan Pengembangan Jalan Indonesia), 3(2).

Mudrikah, Alfiah. (2014). "Kontribusi sektor pariwisata terhadap GDP Indonesia tahun 2004-2009." Economics Development Analysis Journal 3.2.

Munhurrun,P.R.,V,N., Seebaluck., and P. Naidoo.(2014).Examining the structural relationship image, perceived value, tourist satisfaction and loyalty: case of Mauritius. Procedia Social and Behavioral Sciences. 175 (2015); $252-259$

Oskar, Johan \& Jati Pambudi (2014). Analisis Kepuasan Pelanggan Dengan Importance Performance Analysis di SBU Laboratory Cibitung PT Sucofindo (persero) Vol IX, No 1, Januari 2014.

Pendit. (2013). Ilmu Pariwisata (Sebuah Pengantar Perdana). Jakarta: PT Pradnya Paramita

Pohandri, Arie., Sidarto., Winarni. (2013). Analisis Tingkat Kepuasan Pelanggan Dengan Menggunakan Metode Customer Satisfaction Index Dan Importance Performance Analysis Serta Servis Quality. Vol. 1 No. 1, 21 - 29. Jurnal REKAVASI

Prakoso, A. A. (2016). Dampak Multiganda Rencana Induk Pembangunan Kepariwisataan Daerah (RIPPARDA) terhadap 
Kepariwisataan di Daerah Istimewa Yogyakarta. Kepariwisataan: Jurnal Ilmiah, 10(01), 1-26.

Purwaningsi,R.M.(2013).Pengaruh Kualitas Pelayanan Pemandu Wisata terhadap Kepuasan Wisatawan di Candi Prambanan: Tinjauan Khusus pada Kemampuan Berbahasa Verbal.Jurnal Nasinal Pariwisata. Vol. 5 (3) : 146-153.

Rageh, Ahmed dkk.(2013). Using netnography research method to reveal the underlying dimensions of the customer/tourist experience. Qualitative Market Research: An International Journal, Vol. 16 Iss 2 pp. 126 - 149

Rahmi, S. A. (2016). Pembangunan Pariwisata Dalam Perspektif Kearifan Lokal. Reformasi, 6(1).

Rani, P. (2014). Factors influencing consumer behaviour. Institute of Law Kurukshetra, University Kurukshetra Journal, Vol.7 No. 9, 53-61.

Sadeh., et al.(2012).Factors Affecting Tourist Satisfaction and Its onsequences.Journal of Basic and Applied Scientific Research 2 (2) : 1557 - 1560. Saleh Wahab. 2011. Manajemen Pariwisata. PT Pradya Paramitha. Jakarta.

Santoso, S. (2019). Examining relationships between destination image, tourist motivation, satisfaction, and visit intention in Yogyakarta.

Setiawati, Kris. (2021, 24 Maret) Jogja Darurat Sampah, Bukti Membuang Sampah di Tempatnya Saja Tidak Cukup. Diakses dari https://kumparan.com/krismheilda/jogja-darurat-sampah-bukti-membuang- $\quad$ sampah-di-tempatnya-saja-tidak-cukup1vPpuUozVhL [31 Mei 2021]

Sofar Silaen. 2018. Metodologi Penelitian Sosial untuk Penulisan Skripsi dan Tesis. Bogor: IN MEDIA.

Sekaran, Uma dan Roger Bougie, (2017), Metode Penelitian untuk Bisnis: Pendekatan Pengembangan-Keahlian, Edisi 6, Buku 2 , Salemba Empat, Jakarta Selatan 12610.

Sheng, Chieh-Wen dkk. (2013). Tourist experience expectations: questionnaire development and text narrative analysis. International Journal of Culture, Tourism and Hospitality Research, Vol. 7 Iss 1 pp. $93-104$

Stanton, William J. (2016). Prinsip Pemasaran. Edisi Ketujuh, Jilid I. Jakarta:Erlangga

Sudaryono. 2018. Metodologi Penelitian. Depok: PT. Raja Grafindo Persada Sugiyono. (2017). Metode Penelitian Kombinasi (Mixed Methods). Bandung: Alfabeta.

Suryo, Wahyu. (2020, 4 Februari) Aksi Klitih Bikin Pengusaha Wisata Khawatir. Diakses dari https://rri.co.id/yogyakarta/sosial/pariwisata/781940/aksi-klitih- bikin-pengusaha-wisata-khawatir [31 Mei 2021] Suryadana, M Liga dan Octavia Vanny. 2015. Pengantar Pemasaran Pariwisata. Bandung: Alfabet

Suyono, Bambang (2020) Analisis Kepuasan Wisatawan Telaga Sarangan magetan Berdasarkan Tourism Experience

Syakdiah, Syakdiah. (2018). "Dynamics of Tourism in Special District of Yogyakarta." Prosiding Semnasfi 1.1 225-233

Terry, George R dan Leslie W.Rue. 2014. Dasar-Dasar Manajemen, penerjemah G.A Ticoalu. Jakarta: PT Bumi Aksara..

Tjiptono, Fandy dan Gregorius Chandra. (2016). Service Quality and Satisfaction, edisi ketiga. Yogyakarta. Andi

Vellas, Francois dan Becherel, Lionel (2008). Pemasaran Pariwisata Internasional; Sebuah Pendekatan Strategis. Yayasan Obor Indonesia. Jakarta.

Wijayanti Ani, Damanik Janianton (2018): Analysis of the tourist experience of management of a heritage tourism product: case study of the Sultan Palace of Yogyakarta, Indonesia, Journal of Heritage Tourism.

Yudianti Yeti, Rahayu Sugi. (2015). "Peran Dinas Pariwisata Dan Kebudayaan Kota Yogyakarta Dalam Membangun Pariwisata Berbasis Masyarakat (Community Based Tourism)

Zikmund, William G., et al. (2010). Business Research Methods (eighth edition). South Western, USA: Cengage Lear 